\title{
O valor econômico da extração de madeira em tora na Ilha do Marajó, Pará
}

\author{
Antônio Cordeiro de Santana* \\ Ádamo Lima de Santana** \\ Cyntia Meireles de Oliveira**** \\ Marcos Antônio Souza dos Santos ${ }^{* * * * *}$ \\ Mário Miguel Amin ${ }^{* * * * * *}$ \\ Nilson Luiz Costa ${ }^{\text {********t }}$
}

\section{Resumo}

O objetivo deste trabalho foi estimar o valor econômico e a margem de comercialização da madeira em tora oriunda de áreas manejadas. Utilizou-se o preço líquido atualizado da madeira para estimar o valor econômico da exploração florestal madeireira no polo Marajó. Os dados foram obtidos em pesquisa de campo realizada em vinte empresas que operam no local. $\mathrm{O}$ valor econômico médio da extração e comercialização da madeira em pé no mercado local foi de $R \$ 28,46 / \mathrm{m}^{3}$, com um valor mínimo de $R \$ 18,47 / \mathrm{m}^{3}$ para as espécies da categoria C4 (madeira branca) e um máximo de $\mathrm{R} \$ 92,25 / \mathrm{m}^{3}$ para as espécies da categoria C1 (madeira especial). Assim, para um fluxo de trinta anos e extração de $25 \mathrm{~m}^{3} / \mathrm{ha}$ nos planos de manejo das áreas de concessão florestal do estado do Pará, gera-se um valor médio de $\mathrm{R} \$ 688,75 /$ ha. Esse resultado é superior ao gerado pelas atividades de pecuária extensiva (em torno de $\mathrm{R} \$ 180,00 / \mathrm{ha}$ ) e de lavouras de grãos (em torno dos $\mathrm{R} \$ 420,00 / \mathrm{ha}$ ), principais responsáveis pelo desmatamento da Amazônia. A margem de comercialização mostrou que a sociedade tende a se apropriar de $12,4 \%$ do valor econômico gerado na cadeia de madeira oriunda dos contratos de transição.

Palavras-chave: Preço da madeira em tora. Concessão florestal. Viabilidade econômica. Desmatamento. Amazônia.

\footnotetext{
* S.D. Professor da Universidade Federal Rural da Amazônia. E-mail: acsufra@gmail.com Autor para correspondência.

** S.D. Professor da Universidade Federal do Pará. E-mail: adamo@ufpa.br

*** S.D. Professora da Universidade Federal Rural da Amazônia. E-mail: cyntiamei@hotmail.com

***** Me. Professor da Universidade Federal Rural da Amazônia. E-mail: marcos.santos@ufra.edu.br

****** PhD. Professor da Universidade da Amazônia. E-mail: marioamin@gmail.com

******* S.D. Professor da Universidade Federal de Santa Maria. E-mail: ecnilson@msn.com
}

http://dx.doi.org/10.5335/rtee.v22i47.6812

Submissão: 25/04/2015. Aceite: 21/09/2016. 


\section{Introdução}

O setor florestal tem alto peso na economia paraense pelos empregos, renda e divisas que gera. Em 2008, apresentou um valor adicionado de US\$ 4,46 bilhões e gerou 30.481 empregos, participando, respectivamente, com 9,6\% e 3,6\% do PIB e do emprego total do Pará. O comércio nacional e internacional apresentou superávit de US\$ 1,08 bilhão (SANTANA; SANTOS; OLIVEIRA, 2010).

Não obstante essa importância, a efetividade do marco regulatório da exploração florestal na Amazônia, que a partir de 2004 coibiu fortemente o desmatamento e a extração ilegal de madeira em tora, juntamente com os efeitos da crise econômica internacional a partir de 2007 - o mercado paraense de produtos madeireiros diminuiu 64,6\% entre 2007 e 2009 - causaram forte impacto na indústria madeireira, comprometendo o abastecimento do mercado. Para atenuar esse problema de abastecimento e contribuir para a recuperação da indústria madeireira, o Instituto de Desenvolvimento Florestal do Estado do Pará (Ideflor) (2010) implementou a política de gestão de florestas públicas por meio de contratos de concessão florestal. Esses contratos, destinam-se a legalizar e viabilizar a extração e comercialização dos produtos florestais madeireiros e não madeireiros pela iniciativa privada, aplicando as técnicas de manejo florestal sustentável.

Para viabilizar tais contratos, estimou-se o preço da madeira em pé para determinar o valor a ser pago pelas empresas em cada contrato, de acordo com o volume máximo de madeira a ser extraído, estabelecido por meio dos planos de manejo sustentável dessas áreas. Então, o desafio inicial foi estimar o preço da madeira em pé, a partir do preço de mercado da madeira em tora, dos custos de produção e da margem de lucro. De acordo com Santana, Santos e Oliveira (2010a; 2010b), o mercado de madeira em tora do polo madeireiro do Marajó, configurado por vinte serrarias em funcionamento dos municípios de Breves e Portel, opera em concorrência perfeita. Portanto, o valor econômico da atividade madeireira, determinado a partir do preço de equilíbrio desse mercado, reflete o custo de oportunidade dos contratos de concessão florestal.

O dimensionamento do valor econômico da floresta manejada e sua comparação com as principais alternativas de uso das áreas de floresta da Amazônia (pecuária extensiva e agricultura de grãos) deve revelar resultados que confirmam a hipótese de que a exploração sustentável da floresta é mais rentável do que as atividades agropecuárias que, para serem implantadas, exigem a retirada da floresta. Essa hipótese foi comprovada por Santana et al. (2012) para o polo madeireiro do Baixo Amazonas. 
Com isso, a viabilidade econômica da concessão florestal pode contribuir efetivamente para combinar os objetivos de maximização do lucro das empresas com o objetivo da sociedade de tornar mínimo o impacto ambiental das alternativas econômicas de uso do solo no Pará, especificamente na Ilha do Marajó, onde foram implantados os primeiros contratos de transição, gerenciados pelo Ideflor, que são autorizações outorgadas às empresas para manejar e extrair madeira em áreas de florestas públicas do estado do Pará, por um período de cinco anos, após a aprovação dos órgãos ambientais e fundiários.

O objetivo deste trabalho é estimar o valor econômico da extração manejada de madeireira em tora dos contratos de transição do polo madeireiro do Marajó e as margens de comercialização total, social e dos agentes intermediários da cadeia produtiva da madeira.

\section{Valor econômico da floresta manejada}

O setor florestal mundial passa por um processo de reestruturação produtiva com dinâmicas diferenciadas entre os países produtores e consumidores de madeira tropical, em especial na Amazônia, para onde convergem os esforços visando combater a destruição da floresta. Assim, os aspectos da sustentabilidade econômica e ambiental estão mais concretamente incluídos nos contratos de concessão, em função da maior visibilidade do mercado e das ações dos grupos de interesse, porém, os ganhos sociais da participação coletiva e inclusão das populações tradicionais ainda estão no início do percurso. O inventário florestal não identifica o potencial dos produtos não madeireiros. Também não obriga os proprietários dos contratos de concessão a explorar os resíduos de madeira e nem incluir as populações tradicionais locais do entorno dessas áreas de florestas públicas (MONTEIRO et al., 2011).

As dimensões econômica, ambiental e social da sustentabilidade estão determinadas nos documentos oficiais do Instituto Brasileiro do Meio Ambiente e dos Recursos Naturais Renováveis, do Serviço Florestal Brasileiro e do Ideflor, porém a execução deixa em segundo plano ou não contempla parte do capital florestal e as comunidades locais (SANTANA, 2002).

Neste trabalho, combinou-se o conceito de valor econômico à abordagem da cadeia de valor da madeira, adaptado de Porter (1999), envolvendo o conjunto das atividades competitivas implementadas pelas empresas madeireiras, que operam nos elos de produção florestal (manejo e extração) e de desdobramento da madeira em tora (SANTANA et al., 2012; SANTANA, 2012). Esse ponto é de fundamental 
importância para criar vantagem competitiva por parte da indústria madeireira paraense, pois iniciativa do tipo foi adotada pelos demais países produtores de madeira tropical (INTERNATIONAL TROPICAL TIMBER ORGANIZATION, 2008; FOOD AND AGRICULTURE ORGANIZATION OF THE UNITED NATIONS, 2010). Portanto, como estratégia de sobrevivência em longo prazo, a política de concessão florestal deve criar mecanismos para alavancar essa trajetória de desenvolvimento do setor madeireiro da Amazônia (MONTEIRO et al., 2011; AZEVEDO-RAMOS; SILVA; MERRY, 2015).

As empresas que sobreviveram à crise econômica internacional estão incorporando inovações tecnológicas, conforme Santana (2012): (1) no processo de produção de madeira em tora (manejo florestal sustentável e reflorestamento); (2) no desdobramento e beneficiamento da madeira (serrada, laminada, compensada) e (3) na indústria de móveis e artefatos, mediante a incorporação de novos designs, aproveitamento de resíduos (briquetes, pellets, pedaços de madeira) e diferenciação dos produtos finais. Essas ações produziram um amplo processo de reestruturação produtiva na indústria madeireira brasileira, sobretudo, do estado do Pará, que é o maior produtor e exportador de madeira tropical da Amazônia e do Brasil.

O valor econômico estimado no âmbito da cadeia de valor de Porter (1999) contempla o resultado das diversas atividades que se diferenciam do ponto de vista tecnológico, econômico, ambiental e social, que são desenvolvidas ao longo dos processos produtivos e de gestão das empresas. $\mathrm{O}$ valor agregado pela empresa, em cada etapa do processo de produção e comercialização, é mensurado por meio do preço que os clientes estão dispostos a pagar pelo produto. A atividade é economicamente viável quando o valor que a empresa cria é superior ao custo do desenvolvimento da respectiva atividade.

A cadeia de valor contempla três componentes: (1) atividades de apoio; (2) atividades primárias e (3) margem ou valor econômico quando considera o resultado do fluxo líquido atualizado (SANTANA, 2012). As atividades de apoio incluem a implementação e gestão do plano de manejo e os custos de extração e a infraestrutura. As atividades primárias contemplam a logística operacional, o marketing e as vendas, os serviços de certificação do produto e a orientação dos produtos para os mercados nacional e internacional. Por fim a componente margem gera a magnitude da diferença entre o custo unitário e o preço do produto pago pelo cliente, que se transforma em valor econômico líquido ao se considerar o fluxo da exploração manejada de madeira.

Até o momento, como não se conhecia o custo de oportunidade da madeira, em função da extração ilegal, não era possível determinar a competitividade real 
das empresas. Todas as estimativas realizadas até então, conforme Santana et al. (2012), superestimam os benefícios privados e subestimam os benefícios sociais. Para os contratos de transição gerenciados pelo Ideflor, o preço da madeira em pé foi definido com base do preço de equilíbrio do mercado da madeira em tora local, que funciona em concorrência perfeita (SANTANA et al., 2009; SANTANA; SANTOS; OLIVEIRA, 2010a; SANTANA et al., 2011a; SANTANA, 2012). Assim, considerando a extração manejada de madeira, a determinação do valor econômico permite revelar não apenas a viabilidade do negócio, mas a comparação com o valor gerado nas atividades que estão ligadas diretamente ao desmatamento na Amazônia. O argumento principal para o desmatamento é que a rentabilidade da agropecuária é substancialmente superior ao que a floresta é capaz de gerar.

O conceito de valor econômico foi aplicado apenas ao elo da cadeia produtiva de extração manejada de madeira em tora no Marajó. A margem de comercialização contempla os elos de extração e processamento industrial da madeira, nível em que se define o preço equivalente da madeira serrada das espécies extraídas pelas empresas com contratos de concessão florestal do Marajó.

Como os preços da madeira em pé refletem o custo de oportunidade da atividade florestal manejada, as empresas detentoras dos contratos de concessão podem criar vantagem competitiva em relação às demais empresas fora do processo e às demais concorrentes no mercado internacional de madeira tropical (SANTANA; SANTOS; OLIVEIRA, 2010b; SANTANA et al., 2011a, SANTANA et al., 2011b; AZEVEDO-RAMOS; SILVA; MERRY, 2015). Essa perspectiva contribui para que as empresas ampliem o leque de novas espécies florestais a serem introduzidas no mercado de madeira serrada e aumentem a oferta do produto, uma vez que ainda é grande o estoque desse recurso natural nas áreas destinadas às concessões estaduais e federal na Amazônia (SANTANA et al., 2009; MONTEIRO et al., 2011; SANTANA, 2012).

\section{Metodologia}

Neste trabalho, estimou-se o valor econômico da madeira em pé do polo madeireiro do Marajó, com base nos dados disponibilizados nos relatórios de pesquisa produzidos por Santana, Santos e Oliveira (2010a; 2011b), Santana et al. (2011b) e Santana (2012), com o objetivo de estimar o preço da madeira em pé para subsidiar a definição dos editais dos contratos de transição lançados pelo Ideflor. Foram aplicados questionários nas vinte empresas em funcionamento dos municípios de Breves e Portel, em junho de 2011, por ser o período de preços mais baixos para a madeira em tora e para a madeira serrada. Foram obtidas informações sobre o 
preço da madeira em tora, os custos e a gestão dos planos de manejo, o custo de extração de madeira, do transporte das toras e a margem de lucro dos agentes.

Neste trabalho, o valor econômico foi estimado para as espécies florestais encontradas em todas as empresas que passaram pelo processo de entrevistas e com contratos de concessão. Para isso, foram utilizadas as informações do estudo de Santana, Santos e Oliveira (2010a; 2011) e de Santana et al. (2011a), que pioneiramente estimaram o preço da madeira em pé nos polos madeireiros do Marajó e do Baixo Amazonas. O preço da madeira em pé, por recomendação da legislação dos contratos de transição, deve ser atualizado anualmente com base em uma pesquisa de campo, aplicando-se a metodologia proposta por Santana, Santos, Oliveira (2010a). Com o preço da madeira em pé obtido nesses estudos, foi possível estimar o valor econômico da floresta nos contratos de concessão, e compartilhar o resultado com os grupos de interesse que participam da gestão de florestas públicas do estado do Pará. O valor econômico das espécies de madeiras foi obtido por meio da atualização do preço líquido da madeira para um fluxo de trinta anos, recomendado para o ciclo de exploração florestal dos planos de manejo sustentável adotados nos contratos de transição. A fórmula utilizada no cálculo do valor econômico é dada por Pearce, (1990), Santana, Santos e Oliveira (2010a) e Santana (2012):

$$
\left.V E_{i}=\sum_{t=1}^{T} \mid\left(\frac{P_{i t}-C u_{i t}}{(1+r)^{t}}\right) Q_{i t}\right\rfloor=\left(P L a_{i t} \cdot Q_{i t}\right)
$$

em que: $V E_{i}$ é o valor econômico da espécie florestal i; $P L a$ é o preço líquido atualizado da espécie florestal i, no período t, em $\mathrm{R} \$ / \mathrm{m}^{3} ; P$ é o preço da espécie florestal enquadrada na categoria i no mercado local, em $\mathrm{R} \$ / \mathrm{m}^{3}$ (SANTANA et al., 2011a; $C_{u}$ é o custo unitário de produção da espécie florestal i, no mercado local, em $\mathrm{R} \$ / \mathrm{m}^{3}$ (inclui as atividades de manejo, extração e transporte da madeira em tora); $Q$ é o volume médio de madeira extraída pelas empresas da pesquisa, segundo a categoria, estimado em $25 \mathrm{~m}^{3} / \mathrm{ha}$; $r$ é a taxa de desconto que representa o custo de oportunidade do manejo florestal no mercado local (estimada em 8,5\%); $t$ é o horizonte de tempo ( $\mathrm{T}=30$ anos) considerado no ciclo de exploração madeireira nas concessões florestais.

Um valor positivo para $V E$ atesta que a atividade é viável economicamente; um valor zero indica neutralidade do resultado e um valor negativo indica inviabilidade. Assim, para determinar a margem de comercialização da madeira ao longo da cadeia produtiva, foi necessário calcular o preço equivalente da madeira em tora, multiplicando-se o coeficiente de desdobramento pelo preço da madeira serrada, como a seguir, de acordo com Santana et al. (2012) e Santana (2012): 


\section{$P E M_{i}=K_{d} P M S$}

em que: $P E M_{i}$ é o preço equivalente da madeira da espécie i; $K d$ é o coeficiente de desdobramento da madeira $\left(\mathrm{m}^{3}\right.$ de madeira em tora : $\mathrm{m}^{3}$ de madeira serrada) e $P M S_{i}$ é o preço da madeira serrada da espécie i.

A partir desse preço foi possível determinar a margem de comercialização da madeira em tora, que representa quanto do valor pago pela madeira serrada é apropriado pelos agentes da comercialização e quanto se destina à sociedade, no caso, representada pelo governo. A margem de comercialização total $(M C T)$, conforme Santana (2005) representa a remuneração das operações de comercialização realizadas ao longo do canal de distribuição do produto (custos e margens de lucro). A fórmula é a seguinte:

$$
M C T_{i}=\left(\frac{P E M_{i}-P M P_{i}}{P E M_{i}}\right) \times 100
$$

em que $M C T_{i}$ é a margem de comercialização total da espécie de madeira i; $P E M_{i}$ é o preço equivalente da madeira da espécie i e $P M P_{i}$ é o preço da madeira em pé.

Essa margem de comercialização pode ser desmembrada nas margens do intermediário e das empresas. A margem de comercialização do intermediário é dada por:

$$
M \mathrm{Cl}_{i}=\left(\frac{P M T_{i}-P M P_{i}}{P E M_{i}}\right) \times 100
$$

A margem de comercialização da empresa é dada por:

$$
M C E_{i}=\left(\frac{P E M_{i}-P M T_{i}}{P E M_{i}}\right) \times 100
$$

A margem social $(M S)$ de comercialização ou a parcela do preço pago pela madeira serrada que fica com a sociedade é obtida, por diferença:

$$
M C E_{i}=\left(\frac{P E M_{i}-P M T_{i}}{P E M_{i}}\right) \times 100
$$

\section{Resultados e discussão}

Na Tabela 1 constam os resultados das estimativas das quantidades e dos valores econômicos médios das categorias de espécies florestais $\mathrm{C} 1$ (duas espécies), C2 (oito espécies), C3 (10 espécies) e C4 (14 espécies), contemplando as atividades de apoio, atividades primárias e a margem da extração de madeira em tora em áreas manejadas. $\mathrm{O}$ valor econômico $(V E)$ foi medido por hectare e por metro cúbico. 
Os resultados discriminados por espécie florestal constam na Tabela 1A e indicam a viabilidade econômica da extração manejada da madeira em tora. Tabela 1A - Preço líquido atualizado (PLa), Quantidade $(Q)$, Valor econômico (VE), Preços da
madeira em pé $(P M P)$, madeira em tora (PMT), Madeira serrada (PMS) e margens de
comercialização, polo Marajó, estado do Pará, 2011

\begin{tabular}{|c|c|c|c|c|c|c|c|c|c|c|c|}
\hline Nom & Nome científico & PLa & QP & VE & PMP & PMT & PMS & $\mathrm{Kd}$ & MTC & $\mathrm{MCl}$ & MCE \\
\hline Ipê & abebuia serratifolia (Vahl) Nichols. & 1,90 & 0,35 & 25,17 & 85,60 & 262,70 & $1.050,00$ & $38,7 \%$ & $78,9 \%$ & $43,6 \%$ & $35,3 \%$ \\
\hline Cedro & Cedrela odorata $L$. & 91,28 & 0,15 & 13,69 & 86,54 & 287,68 & $1.025,00$ & $40,7 \%$ & $79,2 \%$ & $48,3 \%$ & $31,0 \%$ \\
\hline \multicolumn{2}{|c|}{ Média da Categoria C1 } & 81,59 & 0,25 & 20,40 & 86,07 & 275,19 & $1.037,50$ & $39,7 \%$ & $79,1 \%$ & $45,9 \%$ & $33,1 \%$ \\
\hline Jatobá & Hymenaea courbaril & 41,00 & 1,40 & 57,40 & 57,00 & 180,00 & 793,75 & $30,3 \%$ & $76,3 \%$ & $51,2 \%$ & $25,0 \%$ \\
\hline Cumaru & Dipteryx odorata (Aubl.) Willd. & 31,00 & 0,50 & 15,50 & 51,00 & 168,00 & 815,00 & $33,9 \%$ & $81,5 \%$ & $42,4 \%$ & $39,1 \%$ \\
\hline Freijó & Cordia goeldiana Huber & 34,00 & 0,10 & 3,40 & 51,00 & 173,00 & 850,00 & $33,7 \%$ & $82,2 \%$ & $42,6 \%$ & $39,5 \%$ \\
\hline Angelim & Dinizia excelsa Ducke & 32,00 & 2,50 & 80,00 & 51,00 & 170,00 & 725,50 & $44,0 \%$ & $84,0 \%$ & $37,3 \%$ & $46,7 \%$ \\
\hline Maçaranduba & Manilkara huberi (Ducke) Chevalier & 33,00 & 3,30 & 108,90 & 47,00 & 170,00 & 792,86 & $30,1 \%$ & $80,3 \%$ & $51,5 \%$ & $28,9 \%$ \\
\hline Sucupira & Bowdichia nitida Spruce & 42,50 & 0,20 & 8,50 & 46,00 & 165,50 & 857,14 & $35,1 \%$ & $84,7 \%$ & $39,7 \%$ & $45,0 \%$ \\
\hline Muirac & Astronium ulei Mattick & 33,00 & 0,90 & 29,70 & 45,00 & 162,00 & 785,71 & $38,4 \%$ & $85,1 \%$ & $38,8 \%$ & $46,3 \%$ \\
\hline Louro & Ocotea spixiana (Nees) Mez. & 52,50 & 1,50 & 78,75 & 41,50 & 176,00 & 597,14 & $36,2 \%$ & $80,8 \%$ & $62,3 \%$ & $18,5 \%$ \\
\hline \multicolumn{2}{|c|}{ Média da Categoria C2 } & 37,38 & 1,30 & 48,59 & 48,69 & 170,56 & 777,14 & $35,2 \%$ & $81,9 \%$ & $45,7 \%$ & $36,1 \%$ \\
\hline Goiabão & Pouteria pachycarpa Pires & 28,00 & 0,25 & 7,00 & 36,00 & 149,00 & 555,00 & $37,0 \%$ & $82,5 \%$ & $55,0 \%$ & $27,4 \%$ \\
\hline Itaúba & Mezilaurus itauba (Meisn.) Taub. ex Mez & 30,00 & 0,70 & 21,00 & 35,00 & 147,00 & 725,00 & $47,0 \%$ & $89,7 \%$ & $32,9 \%$ & $56,9 \%$ \\
\hline Andiroba & Carapa guianensis Aubl. & 16,50 & 0,70 & 11,55 & 33,50 & 130,00 & 662,00 & $38,6 \%$ & $86,9 \%$ & $37,8 \%$ & $49,1 \%$ \\
\hline Pau Roxo & Peltogyne paradoxa Ducke & 26,00 & 0,20 & 5,20 & 32,00 & 140,00 & 705,00 & $34,2 \%$ & $86,7 \%$ & $44,8 \%$ & $41,9 \%$ \\
\hline Amarelão & Apuleia leiocarpa (Vogel) J.F.Macbr. & 12,00 & 0,60 & 7,20 & 31,00 & 125,00 & 600,00 & $34,0 \%$ & $84,8 \%$ & $46,1 \%$ & $38,7 \%$ \\
\hline Quaruba & Vochysia paraensis Ducke & 29,50 & 0,80 & 23,60 & 30,50 & 140,00 & 501,67 & $46,3 \%$ & $86,9 \%$ & $47,2 \%$ & $39,7 \%$ \\
\hline Cedrorana & Vochysia maxima Ducke & 24,00 & 0,25 & 6,00 & 27,50 & 130,00 & 556,25 & $39,9 \%$ & $87,6 \%$ & $46,2 \%$ & $41,4 \%$ \\
\hline Pau Amarelo & Euxylophora paraensis & 26,00 & 1,75 & 45,50 & 27,00 & 135,00 & 707,50 & $34,0 \%$ & $88,8 \%$ & $44,9 \%$ & $43,9 \%$ \\
\hline Tatajuba & Bagassa guianensis Aubl. & 16,00 & 0,50 & 8,00 & 24,00 & 123,00 & 721,67 & $35,8 \%$ & $90,7 \%$ & $38,3 \%$ & $52,4 \%$ \\
\hline Jarana & Lecythis lurida (Miers) S.A.Mori & 22,00 & 0,45 & 9,90 & 22,00 & 130,00 & 640,00 & $37,0 \%$ & $90,7 \%$ & $45,6 \%$ & $45,1 \%$ \\
\hline \multicolumn{2}{|c|}{ Média da Categoria C3 } & 23,00 & 0,62 & 14,26 & 29,85 & 134,90 & 637,41 & $38,4 \%$ & $87,5 \%$ & $43,9 \%$ & $43,6 \%$ \\
\hline & Goupia glabra Aubl. & 22,50 & 1,05 & 23,63 & 18,00 & 115,00 & 622,00 & $40,3 \%$ & $92,8 \%$ & $38,7 \%$ & $54,1 \%$ \\
\hline Curu & Micropholis nelioniana & 16,00 & 0,10 & 1,60 & 18,00 & 115,00 & 733,50 & $33,0 \%$ & $92,6 \%$ & $40,1 \%$ & $52,5 \%$ \\
\hline Cop & Copaifera guianensis Desf. & 16,50 & 0,10 & 1,65 & 17,50 & 115,00 & 500,00 & $34,0 \%$ & $89,7 \%$ & $57,4 \%$ & $32,4 \%$ \\
\hline Tauarí & Couratari guianensis Aubl. & 23,50 & 1,10 & 25,85 & 16,50 & 115,00 & 587,50 & $39,5 \%$ & $92,9 \%$ & $42,4 \%$ & $50,4 \%$ \\
\hline Tanimbuca & Terminalia amazonica & 15,00 & 0,50 & 7,50 & 16,00 & 110,00 & 607,50 & $39,3 \%$ & $93,3 \%$ & $39,4 \%$ & $53,9 \%$ \\
\hline Taxi & Triplaris surinamensis Cham. & 9,00 & 0,50 & 4,50 & 16,00 & 105,00 & 575,00 & $37,0 \%$ & $92,5 \%$ & $41,8 \%$ & $50,6 \%$ \\
\hline Melancieira & Alexa grandiflora Ducke & 18,00 & 0,10 & 1,80 & 16,00 & 114,00 & 540,00 & $33,0 \%$ & $91,0 \%$ & $55,0 \%$ & $36,0 \%$ \\
\hline Timborana & Piptadenia suaveolens Miq. & 19,50 & 0,90 & 17,55 & 15,50 & 110,00 & 506,00 & $44,8 \%$ & $93,2 \%$ & $41,7 \%$ & $51,5 \%$ \\
\hline Marupá & Simarouba amara Aubl. & 18,50 & 0,45 & 8,33 & 15,50 & 114,00 & 593,50 & $32,8 \%$ & $92,0 \%$ & $50,6 \%$ & $41,4 \%$ \\
\hline Garapeira & Apuleia leiocarpa (Vogel) J.F.Macbr. & 5,00 & 0,45 & 2,25 & 15,00 & 100,00 & 700,00 & $32,3 \%$ & $93,4 \%$ & $37,6 \%$ & $55,8 \%$ \\
\hline Faveira & Piptadenia suaveolens Miq. & 13,00 & 1,10 & 14,30 & 15,00 & 110,00 & 433,50 & $29,5 \%$ & $88,3 \%$ & $74,3 \%$ & $14,0 \%$ \\
\hline Piquiá & Caryocar microcarpum Ducke & 33,00 & 0,70 & 23,10 & 15,00 & 128,00 & 593,00 & $38,8 \%$ & $93,5 \%$ & $49,1 \%$ & $44,4 \%$ \\
\hline Mandioqueira & Qualea lancifolia Ducke & 17,00 & 0,35 & 5,95 & 15,00 & 114,00 & 533,50 & $41,6 \%$ & $93,2 \%$ & $44,6 \%$ & $48,6 \%$ \\
\hline Ucuúba & Virola melinonii (R.Benoist) & 18,00 & 0,50 & 9,00 & 15,00 & 105,00 & 575,00 & $34,0 \%$ & $92,3 \%$ & $46,0 \%$ & $46,3 \%$ \\
\hline \multicolumn{2}{|c|}{ Média da Categoria C4 } & 17,46 & 0,56 & 9,85 & 16,00 & 112,14 & 578,57 & $36,4 \%$ & $92,2 \%$ & $47,1 \%$ & $45,1 \%$ \\
\hline \multicolumn{2}{|c|}{ Média geral } & 27,55 & 0,74 & 20,26 & 31,89 & 142,17 & 669,59 & $36,9 \%$ & $87,6 \%$ & $45,7 \%$ & $41,9 \%$ \\
\hline
\end{tabular}

Fonte: Santana, Santos e Oliveira (2010a, 2011a). 
A média geral dos resultados mostra que foi extraído $0,74 \mathrm{~m}^{3} /$ ha de madeira em tora por espécie florestal, gerando um $V E$ médio para todas as espécies de $\mathrm{R} \$$ $20,26 /$ ha ou $R \$ 27,55 / \mathrm{m}^{3}$. Considerando todas as espécies e a extração de $25 \mathrm{~m}^{3} / \mathrm{ha}$, em fluxo econômico de trinta anos, nas áreas manejadas dos contratos de concessão, gera-se um valor econômico de $\mathrm{R} \$ 688,75 /$ ha. Esse valor é superior ao gerado pelas atividades que concorrem para a retirada da floresta, como soja ( $\mathrm{R} \$ 420,00$ / ha) e pecuária extensiva ( $\mathrm{R} \$ 180,00 / \mathrm{ha}$ ) (SANTANA; AMIN, 2002; SANTANA et al., 2009; SANTANA et al., 2012; SANTANA, 2012; OLIVEIRA; SANTANA; HOMMA, 2013). Esse resultado é diferente dos relacionados na literatura, conforme Karsenty et al. (2008), em que a floresta manejada gera uma renda inferior às atividades agrícola, pecuária e de reflorestamento. Especialmente na Amazônia, onde ainda não se conhece o valor econômico da atividade florestal madeireira, já que sob o sistema tradicional de derruba e queima da floresta, o preço das árvores é próximo de zero.

Tabela 1 - Quantidade extraída de madeira e valor econômico da madeira em tora dos contratos de concessão do polo Marajó, estado do Pará

\begin{tabular}{l|c|c|c|c}
\hline \multicolumn{1}{c|}{ Valor médio } & $\begin{array}{c}\text { Número de } \\
\text { espécies }\end{array}$ & $\begin{array}{c}\text { Quantidade } \\
Q\left(\mathrm{~m}^{3} / \mathrm{ha}\right)\end{array}$ & $\begin{array}{c}\text { Valor econômico } \\
V E a(\mathrm{R} \$ / \mathrm{ha})\end{array}$ & $\begin{array}{c}\text { Valor econômico } \\
V E b\left(\mathrm{R} \$ / \mathrm{m}^{3}\right)\end{array}$ \\
\hline Categoria C1 & 2 & 0,25 & 20,40 & 81,59 \\
Categoria C2 & 8 & 1,30 & 48,59 & 37,38 \\
Categoria C3 & 10 & 0,62 & 14,26 & 23,00 \\
Categoria C4 & 14 & 0,56 & 9,85 & 17,46 \\
\hline Média geral & 34 & 0,74 & 20,26 & 27,55 \\
\hline
\end{tabular}

Nota: $V E a=$ resultado por hectare; $V E b=$ resultado por $\mathrm{m}^{3} ; P L a=$ preço liquido atualizado.

Fonte: elaborado com base em Santana, Santos e Oliveira (2010b) e Santana et al. (2011b).

Nos sistemas de uso do solo na Amazônia, a venda das árvores de maior valor comercial para os madeireiros geralmente se destina a custear parte do desmatamento e de implantação das atividades agrícolas e das pastagens para a criação de gado (SANTANA, 2002). Confirmam-se, portanto, os resultados de Santana (2008) e Santana et al. (2012) de que a agricultura tradicional e a pecuária extensiva praticadas na Amazônia desenvolvem-se às custas da exploração dos recursos naturais e da mão de obra informal.

A extração florestal madeireira regulada pelos contratos de transição também pode apresentar maior rentabilidade do que o reflorestamento. Um reflorestamento com paricá implantado na microrregião de Paragominas, com fluxo de 28 anos, 
produtividade de $200 \mathrm{~m}^{3} /$ ha e preço de $\mathrm{R} \$ 70,00 / \mathrm{m}^{3}$, gera margem de valor econômico de $\mathrm{R} \$ 192,26 /$ ha (VALE, 2010). Portanto, a gestão de florestas públicas por meio dos contratos de concessão é uma alternativa economicamente viável, que deve se integrar ao sistema produtivo e diversificado de base agrária do estado do Pará.

Observa-se pelos resultados da Tabela 1, que mesmo na situação em que a floresta manejada contemple apenas madeira branca (categoria $\mathrm{C} 4$ ), o valor econômico total estimado seria de $\mathrm{R} \$ 436,50 /$ ha, portanto, superior ao gerado nas alternativas de produção agropecuária. A razão para a maior rentabilidade econômica deve-se ao baixo custo de produção, uma vez que a dependência de insumos modernos é insignificante fora do ano em que se realiza a colheita das árvores.

Como em todas as áreas de concessão constam espécies das quatro categorias, a extração manejada de madeira na Amazônia torna-se economicamente viável, o que deve despertar o interesse dos empresários e dos órgãos de fomento para investir nesse negócio. Sendo assim, observa-se que na categoria C1, que contempla as madeiras especiais cedro e ipê, tem-se o maior $V E$ médio da produção por metro cúbico ( $R \$ 81,59)$, em função da grande demanda, que assegura uma elevada cotação no mercado de madeira tropical. Por outro lado, gera um $V E$ por hectare (R $\$ 20,40$ / ha) entre as categorias, dada a escassez dessas espécies florestais nas áreas de manejo (produção media de $0,25 \mathrm{~m}^{3} / \mathrm{ha}$ ), por causa do longo período de extração ilegal.

As categorias $\mathrm{C} 2$ e $\mathrm{C} 3$ abrigam as madeiras nobres e vermelhas, demandadas pela construção civil rural e urbana, indústria de móveis e artefatos, cercas rurais, etc., tanto no mercado nacional quanto internacional. As espécies da categoria C2 apresentam a maior produção media $\left(1,30 \mathrm{~m}^{3} / \mathrm{ha}\right)$ e $V E$ médio ( $\left.\mathrm{R} \$ 48,59 / \mathrm{ha}\right)$. A categoria C4 (madeira branca), por sua vez, engloba as espécies de menor valor comercial, porém têm ampla utilização na produção de laminados, compensados e artefatos de madeira. Atualmente, em função da crise financeira e econômica global, a indústria de laminados e compensados de madeira tropical foi fortemente abalada, o que propiciou à indústria de madeira serrada inserir no mercado brasileiro algumas dessas espécies. Tais espécies, inclusive, substituíram madeiras enquadradas nas categorias anteriores, tanto para a cobertura de residências como matéria-prima na indústria de móveis e artefatos. Como resultado, essa categoria de madeira já representa a segunda maior quantidade média produzida nas áreas manejadas $\left(0,56 \mathrm{~m}^{3} / \mathrm{ha}\right)$, gerando um $V E$ médio por espécie de $\mathrm{R} \$ 9,85 / \mathrm{ha}$. $\mathrm{O} V E$ médio de $R \$ 17,46 / \mathrm{m}^{3}$ é superior ao preço de $\mathrm{R} \$ 10,00 / \mathrm{m}^{3}$ que se paga por metro cúbico de madeira especial ou nobre extraída ilegalmente das áreas não manejadas. 
Por outro lado, esse valor econômico, além de subestimado, apresenta limitações em termos da distribuição da renda com as comunidades locais, dado que não foram computados o valor dos resíduos da extração madeireira, geralmente destinada à produção de lenha e carvão, e o valor dos produtos não madeireiros. Esses produtos constituem um canal importante, com a inserção das populações tradicionais para alavancar a indústria de móveis, artesanatos e de produção de energia a partir da biomassa, o que contribui para fortalecer o desenvolvimento local.

\section{Margem de comercialização da madeira em tora}

A Tabela 2 resume os resultados para as margens de comercialização e o coeficiente de desdobramento da madeira, utilizado para estimar o preço equivalente da madeira serrada. Esse coeficiente é um indicador do nível tecnológico das empresas entrevistadas. Quanto maior o $K_{d}$, maior é o aproveitamento da madeira em tora e, consequentemente, menor o volume de resíduo produzido. Os resultados por espécie florestal encontram-se na Tabela 1A.

Observa-se que a $M C T$ apresentou comportamento inverso ao do $V E$ das madeiras, em que o maior valor foi atribuído às espécies de menor valor econômico da $\mathrm{C} 4$ e o menor das espécies da $\mathrm{C} 1$. Isto ocorre em função dos custos de processamento e dos riscos para a inserção do produto no mercado, uma vez que sua utilização no mercado ainda é limitada.

Tabela 2 - Coeficiente de desdobramento e margens de comercialização da madeira em tora do Marajó, estado do Pará

\begin{tabular}{l|c|c|c|c|c}
\hline \multicolumn{1}{c|}{ Valor médio } & Kd & MCT & MCl & MCE & MS \\
\hline Média da categoria C1 & $39,7 \%$ & $79,1 \%$ & $45,9 \%$ & $33,1 \%$ & $20,9 \%$ \\
Média da categoria C2 & $35,2 \%$ & $81,9 \%$ & $45,7 \%$ & $36,1 \%$ & $18,1 \%$ \\
Média da categoria C3 & $38,4 \%$ & $87,5 \%$ & $43,9 \%$ & $43,6 \%$ & $12,5 \%$ \\
Média da categoria C4 & $36,4 \%$ & $92,2 \%$ & $47,1 \%$ & $45,1 \%$ & $7,8 \%$ \\
\hline Média geral & $36,9 \%$ & $87,6 \%$ & $45,7 \%$ & $41,9 \%$ & $12,4 \%$ \\
\hline
\end{tabular}

Nota: Kd é o coeficiente de desdobramento da madeira em tora; MCT é a margem de comercialização total; $M C l$ é a margem de comercialização do intermediário; MCE é a margem de comercialização do empresário e MS é a margem social.

Fonte: elaborado a partir de Santana, Santos e Oliveira (2010b) e Santana et al. (2011b).

A margem de comercialização dos intermediários $(M C I)$ é atribuída aos produtores que vendem madeira em tora no mercado local, ou dos extratores que adquirem a madeira de comunidades locais e de planos de manejo (conhecidos como "toreiros"), mas que não fazem o desdobramento da madeira. Por isso, respondem pela 
maior parcela da margem de comercialização, uma vez que arcam com os custos de extração da madeira e transporte até a beira dos rios ou das estradas vicinais para o embarque do produto. Para esses agentes, as espécies enquadradas nas C2 e C3 apresentam as menores margens de comercialização e nas categorias C1 e C4 as maiores. As espécies da categoria $\mathrm{C} 1$ apresentam maiores custos de extração, transporte, impostos, e o preço da madeira em tora é relativamente mais alto do que das espécies da categoria $\mathrm{C} 4$. Por outro lado, a categoria C4 apresenta custos e margens de lucro mais elevados em função do alto risco de preço do mercado da madeira em tora.

No caso dos empresários que adquirem a madeira em tora a margem de comercialização $(M C E)$ é menor do que a margem do intermediário, porque se adiciona ao preço da madeira em tora apenas os custos de transporte e do desdobramento da madeira. A margem cresce no mesmo sentido da $M C T$, com a menor margem para as madeiras da C1 e a maior para as madeiras da categoria C4. Por outro lado, as empresas verticalizadas realizam todas as etapas da extração ao desdobramento e se apropriam de toda a margem de comercialização. Assim, a madeireira busca equilibrar sua margem de lucro com as madeiras de menor valor comercial, uma vez que os estoques naturais dessas árvores são substancialmente mais abundantes e diversificados. Esse resultado explica as razões para a representação dos madeireiros que têm contratos de transição reivindicar uma redução dos preços das madeiras de menor valor comercial.

A margem social (MS), ou margem apropriada pelo produtor rural ou caboclo da Amazônia, caminha no sentido inverso da $M C T$, tendo maior participação no negócio das madeiras situadas nas categorias mais nobres. A média geral de ${ }_{d}=36,9 \%$ indicou que são necessários $2,71 \mathrm{~m}^{3}$ de madeira em tora para produzir $1,0 \mathrm{~m}^{3}$ de madeira serrada. Esse resultado deve-se ao baixo padrão tecnológico das empresas e aos problemas de rachadura, ocos e nós das toras.

A $M C T$ de $87,6 \%$ indica que para cada $\mathrm{R} \$ 1.000,00$ que os clientes gastam na aquisição de madeira serrada, $\mathrm{R} \$ 876,00$ são apropriados pelos agentes da comercialização, distribuídos entre os intermediários $(R \$ 457,00)$ e os empresários ( $\mathrm{R} \$ 419,00)$, e $\mathrm{R} \$ 124,00$ ficam com os produtores. Portanto, a sociedade apropria-se de $12,4 \%$ do valor total do negócio da madeira produzida nos contratos de concessão do Marajó.

Os resultados das pesquisas de campo, conforme Santana, Santos e Oliveira (2010b) e Santana et al. (2011b), revelaram um número considerável de espécies florestais que antes era enquadrada como madeira branca e desconhecida do mercado de madeira serrada pelas indústrias de móveis, artefatos e da construção civil. Atualmente, essas madeiras estão atingindo parcela do mercado em função 
da coloração e da adequação à fabricação de móveis e artefatos, como madeira para cobertura de casas, fabricação de portas, janelas, lambris, entre outros produtos. Portanto, algumas empresas estão criando vantagem competitiva com base nas oportunidades que surgiram com a crise financeira internacional e com a nova dinâmica da política ambiental brasileira.

\section{Conclusões}

O valor econômico médio da extração manejada de madeira em tora no Marajó foi de $R \$ 27,55 / \mathrm{m}^{3}$, assumindo um valor mínimo de $\mathrm{R} \$ 17,46 / \mathrm{m}^{3}$ para as espécies da categoria $\mathrm{C} 4$ e um máximo de $\mathrm{R} \$ 81,59 / \mathrm{m}^{3}$ para as espécies da categoria $\mathrm{C} 1$. Assim, para uma extração de $25 \mathrm{~m}^{3} /$ ha de madeira nas áreas de florestas manejadas dos contratos de concessão do estado do Pará, em fluxo econômico de trinta anos, gera-se um valor econômico de $\mathrm{R} \$ 688,74 /$ ha. Esse resultado é superior ao gerado pelas atividades de pecuária extensiva e de lavoura de grãos, principais responsáveis pelo desmatamento da Amazônia.

Conclui-se, portanto, que a extração manejada de madeira das áreas de concessão florestal do estado do Pará, ao contrário do esperado, apresenta valor econômico superior à agricultura tradicional de grãos e a pecuária extensiva, o que sinaliza para a eficiência econômica da gestão de florestas públicas na Amazônia.

Os produtores de madeira em tora e a produção comunitária dominam, em média, $12,4 \%$ do valor econômico do negócio da madeira e os $87,6 \%$ restantes ficam com as empresas florestais. No caso dos contratos de transição, a sociedade apropria-se de $12,4 \%$ desse negócio. Assim, a cada $R \$ 1.000,00$ gastos na aquisição de madeira serrada, $R \$ 124,00$ ficam com a sociedade (valor arrecadado pelo governo) e $R \$ 876,00$ ficam com os intermediários e empresários do setor florestal.

Finalmente, conclui-se que a política de concessão florestal apresenta viabilidade mesmo subestimando o valor socioeconômico e ambiental da floresta uma vez que apenas a madeira em tora está em pauta. 


\title{
The economic value of the roundwood extraction in the Marajó Island in the state of Pará
}

\begin{abstract}
The aim of this study is to estimate the economic value and marketing margins of roundwood from managed areas. We used the net present price of timber to estimate the economic value of logging in polo Marajó. The data were obtained from field research conducted in 20 companies in operation on site. The results indicate that the average economic value of extraction and sale of standing timber, on the local market, is $R \$ 28,46 / \mathrm{m}^{3}$, which shows a minimum value of $\mathrm{R} \$ 18,47 / \mathrm{m}^{3}$ for the species of the $\mathrm{C} 4$ category (white wood) and a maximum value of $R \$ 92,25 / \mathrm{m}^{3}$ for species of the $\mathrm{C} 1$ category (special wood). Thus, for a flow of 30 years and an extraction rate of $25 \mathrm{~m}^{3} /$ ha, under the managed forest transition areas in the State of Pará, an average value of $\mathrm{R} \$ 688,75 /$ ha is noted. This result is relatively higher than the values obtained from extensive livestock farming (around $\mathrm{R} \$ 180,00 / \mathrm{ha}$ ) and grain crop cultivation (around $\mathrm{R} \$ 420,00 / \mathrm{ha}$ ), which are largely responsible for Amazonian deforestation. The marketing margin shows that about $12.4 \%$ of the economic value generated from the timber's supply chain transition contracts, is appropriated by society. Additionally, the mean rate of unfolding of $36.2 \%\left(2.76 \mathrm{~m}^{3}\right.$ of logs for each $1.0 \mathrm{~m}^{3}$ of lumber), indicates poor technological advancements, which threatens enterprises' market competitiveness.
\end{abstract}

Keywords: Price of roundwood. Transition contracts. Economic viability. Deforestation. Amazon.

\section{El valor económico de la extracción de madera en rollo en la Isla de Marajó en el estado de Pará}

\section{Resumen}

\begin{abstract}
El objetivo de este estudio fue estimar el valor económico y la margen de comercialización de madera en rollo procedentes de zonas administradas. Se utilizó el precio actual neto de la madera para estimar el valor económico de la extracción de madera en el Polo Marajó. Los datos fueron obtenidos de la investigación de campo realizada en 20 empresas en funcionamiento en el sitio. O valor económico positivo demuestra la viabilidad del negocio. El valor económico medio de la extracción y venta de madera en pie en el mercado local fue de $\mathrm{R} \$ 28.46 / \mathrm{m} 3$, con un valor mínimo de $\mathrm{R} \$ 18.47 / \mathrm{m} 3$ para las especies de la categoría $\mathrm{C} 4$ (madera blanca) y un máximo $\mathrm{R} \$ 92,25 / \mathrm{m} 3$ para las especies de la categoría $\mathrm{C} 1$ (madera especial). Por lo tanto, para un periodo de 30 años y extracción de $25 \mathrm{~m} 3 /$ ha en los planes de manejo de las áreas de concesión forestal del estado de Pará, se genera un valor promedio de $\mathrm{R} \$ 688,75 /$ ha. Este resultado es relativamente mayor que el generado por las actividades de ganadería extensiva (cerca de $\mathrm{R} \$ 180.00 / \mathrm{ha}$ ) y de cultivos de cereales (cerca de $\mathrm{R} \$$ 420.00/ha), principales responsables por la deforestación de la Amazonia. La margen de comercialización demostró que la sociedad tiende a apropriarse de $12,4 \%$ del valor económico generado en la cadena de madera derivado de contratos de transición.
\end{abstract}

Palabras clave: Precio de la madera en rollo. Concesiones forestales. Viabilidad económica. Deforestación. Amazonía. 


\section{Referências}

AZEVEDO-RAMOS, C.; SILVA, J. N. M.; MERRY, F. The extinction of deforestation in the Brazilian Amazon: Is it possible? Elementa: Science of the Anthropocene, Washington, DC, v. 3, n. 48 , p. 1-8, 2015.

FOOD AND AGRICULTURE ORGANIZATION OF THE UNITED NATIONS. Evaluación de los recursos forestales mundiales. 2010. Disponível em: <http://www.fao.org/forestry/fra2020>. Acesso em: maio 2010.

INSTITUTO DE DESENVOLVIMENTO FLORESTAL DO ESTADO DO PARÁ. Ideflor. Orientação de pagamento: contratos de transição. 2010. Disponível em: <www.ideflorbio.pa.gov.br>. Acesso em: 8 mar. 2010.

INTERNATIONAL TROPICAL TIMBER ORGANIZATION. Annual review and assessment of the world timber situation, 2008. Disponível em: <http://www.itto.org.jp/>. Acesso em: 5 jul. 2010.

KARSENTY, A. et al. Regulating industrial forest concessions in Central Africa and South America. Forest ecology and Management, Sydney, v. 256, p. 1.498-1.508, 2008. Disponível em: <www.journals.elsevier.com/forest-ecology-and-management>. Acesso em: 13 ago. 2010.

MONTEIRO, L. C. et al. Análise crítica e proposições para a gestão sustentável dos contratos de concessão de florestas públicas no Pará. Amazônia: Tecnologia \& Desenvolvimento, Belém, v. 7, n. 1, p. 129-145, 2011.

OLIVEIRA, C. M.; SANTANA, A. C.; HOMMA, A. K. O. Os custos de produção e a rentabilidade da soja nos municípios de Santarém e Belterra, estado do Pará. Acta Amazonica, Manaus, v. 43, n. 1, p. 23-32, 2013.

PEARCE, D. W. Environmental sustainability and cost benefit analysis. Environment and planning, Los Angeles, v. 22, n. 1, p. 97-112, 1990.

PORTER, M. E. Vantagem competitiva. Rio de Janeiro: Campus, 1999.

SANTANA, A. C. A competitividade sistêmica das empresas de madeira da Região Norte. Belém: FCAP, 2002. 304 p.

SANTANA, A. C. Cadeias produtivas setoriais e o curso do desenvolvimento local na Amazônia In: ALBUQUERQUE, A. C. S.; SILVA, A. G. (ed.). Agricultura tropical: quatro décadas de inovações tecnológicas, institucionais e políticas. Brasília: EMBRAPA, 2008. p. 275-291. v. 2.

2005. 197 p.

Elementos de economia, agronegócio e desenvolvimento local. Belém: GTZ/TUD/UFRA, . Valoração econômica e mercado de recursos florestais. Belém: UFRA, 2012. 226 p.

SANTANA, A. C.; SANTOS, M. A. S.; OLIVEIRA, C. M. Preço da madeira em pé, valor econômico e mercado de madeira nos contratos de transição do estado do Pará. Belém: IDEFLOR/UFRA, 2010a. 114p.

SANTANA, A. C.; SANTOS, M. A. S.; OLIVEIRA, C. M. Comportamento histórico da produção e comércio de madeira do estado do Pará e nos mercados local e internacional. Amazônia: Ciência \& Desenvolvimento, Belém, v. 6, n. 1, p. 63-90, 2010 b. 
SANTANA, A. C.; SANTOS, M. A. S.; OLIVEIRA, C. M. Diagnóstico para estimar preços de madeira em pé e criar categorias com base no valor comercial das regiões do Marajó e do Baixo Amazonas, estado do Pará. Belém: IDEFLOR/FUNPEA, 2011. 62 p.

SANTANA, A. C.; AMIN, M. M. Cadeias produtivas e oportunidades de negócio na Amazônia. Belém: Unama, 2002. 454 p.

SANTANA, A. C. et al. Determinação dos preços da madeira em pé para as áreas de florestas públicas da região do Baixo Amazonas, no estado do Pará. Revista de Estudos Sociais, Cuiabá, v. 13 , n. 1, p. 40-51, 2011a.

SANTANA, A. C. et al. Estimação dos preços da madeira em pé para as áreas de florestas públicas da região do Marajó, no estado do Pará. Amazônia: Tecnologia \& Desenvolvimento, Belém, v. 6 , n. 1., p. 7-19, 2011b.

SANTANA, A. C. et al. O valor econômico da extração manejada de madeira no Baixo Amazonas, estado do Pará. Revista Árvore, Viçosa, v. 36, n. 3, p. 527-536, 2012.

SANTANA, A. C. et al. A sustentabilidade do desempenho competitivo das madeireiras da região Mamuru-Arapiuns, estado do Pará. Teoria e Evidência Econômica, Passo Fundo, v. 15, n. 1, p. 9-36, 2009.

VALE, F. A. F. Sustentabilidade de sistemas de produção florestal no estado do Pará. Dissertação (Mestrado em Ciências Florestais) - Universidade Federal Rural da Amazônia, Belém, 2010. $112 \mathrm{p}$. 